\title{
Incidence and Risk Factors of Intracranial Atherosclerotic Stroke: The Northern Manhattan Stroke Study
}

\author{
Fred Rincon ${ }^{a}$ Ralph L. Sacco ${ }^{e}$ Grace Kranwinkel $^{b}$ Qiu Xu ${ }^{c}$ Myungee C. Paik ${ }^{c}$ \\ Bernadette Boden-Albalab, ${ }^{b}$ Mitchell S.V. Elkind ${ }^{b}$ \\ ${ }^{a}$ Department of Medicine, Division of Critical Care and Cardiovascular Medicine, Robert Wood Johnson \\ Medical School, UMDNJ, Camden, N.J., b Department of Neurology, Columbia University College of Physicians and \\ Surgeons, and Departments of ${ }^{\mathrm{C} B i o s t a t i s t i c s}$ and ${ }^{\mathrm{d}}$ Sociomedical Science, Mailman School of Public Health, \\ Columbia University, New York, N.Y., and e Department of Neurology, Miller School of Medicine, \\ University of Miami, Miami, Fla., USA
}

\section{Key Words}

Atherosclerosis $\cdot$ Ischemic stroke $\cdot$ Metabolic syndrome $\cdot$

Diabetes mellitus

\begin{abstract}
Background: To assess the prevalence of risk factors as determinants of intracranial atherosclerosis (IATH)-related stroke in a multi-ethnic community-based cohort. Methods: The Northern Manhattan Stroke Study included a population-based incidence study and a nested case-control study. Incident cases of first ischemic stroke were 1:2 when matched to community controls by age, sex, and race/ethnicity. Vascular risk factors were assessed among controls and compared against the following stroke subtypes: IATH, extracranial atherosclerosis (EATH), and non-atherosclerotic (NATH: cardioembolic, lacunar, and cryptogenic). Conditional logistic-regression was used to determine the association between risk factors and stroke subtypes. Results: The crude incidence of IATH was $8 / 100,000$ per year and the relative incidence of IATH was higher than that of EATH in blacks (5.9 vs. 3.2/100,000 per year) and in Hispanics (5.0 vs. 1.7/100,000 per year). The IATH group had a higher prevalence of diabetes mellitus (DM; 67\% IATH, 60\% EATH, 48\% NATH, and 23\%
\end{abstract}

controls; $\mathrm{p}<0.05$ IATH vs. control) and of metabolic syndrome (62\% IATH, 40\% EATH, 40\% NATH, and 35\% controls; $\mathrm{p}<0.05$ IATH vs. control). In multivariate analysis, DM conferred a higher risk for IATH versus NATH stroke (OR, 10.8; $95 \% \mathrm{Cl}, 2.0-57$ vs. OR, $2.7 ; 95 \% \mathrm{Cl}, 1.9-3.9 ; \mathrm{p}<0.05)$ and much lower for EATH (OR, 6.2; $95 \% \mathrm{Cl}, 1.2-32)$. The metabolic syndrome conferred a higher risk for IATH stroke subtype (OR, 4.6; $95 \% \mathrm{Cl}, 1.1-18.7)$ when compared to EATH (OR, 2.3; $\mathrm{Cl}$, 0.6-9.1) and NATH (OR, 2.4; Cl, 1.7-3.3). Conclusions: DM is a more important determinant for IATH-related stroke than EATH or NATH.

Copyright $\odot 2009$ S. Karger AG, Basel

\section{Introduction}

Intracranial atherosclerosis (IATH) has been recognized as a serious cause of stroke. Several studies have demonstrated that IATH is present in $7-10 \%$ of patients with cerebrovascular disease $[1,2]$, and that certain subgroups of the general population, such as blacks [2-4], Hispanics [2, 3], and Asians (Japanese, Chinese, and Korean descent) $[5,6]$ have significantly higher incidence rates of IATH compared to whites.

\section{KARGER}

๑) 2009 S. Karger AG, Basel

Fax +4161306 1234 E-Mail karger@karger.ch www.karger.com www.karger.com/ced
Fred Rincon, MD

Department of Medicine

Robert Wood Johnson Medical School - UMDNJ

401 Haddon Ave., Rm. 242, Camden, NJ 08103 (USA)

Tel. +1 856757 7967, Fax +1 856968 9587, E-Mail rincon-fred@cooperhealth.edu 
In general, the risk factors are thought to be the same as for non-intracranial vascular disease, and include hypertension (HTN), hypercholesterolemia, tobacco smoking, and diabetes mellitus (DM), in addition, possibly, to genetic factors and race-ethnicity [2-7]. Recently, the metabolic syndrome [8], a cluster of risk factors that are linked to insulin resistance and increased risk of coronary heart disease [9] and stroke [10], has been implicated as an independent predictor of IATH in Asian patients of Korean descent [5].

Whether the variation in the prevalence of classic cardiovascular risk factors across race-ethnic groups explains the greater incidence of IATH in certain groups is still unknown. The aim of this investigation was to explore the prevalence and significance of risk factors as determinants of IATH-related stroke in a multi-ethnic community-based cohort.

\section{Methods}

The Northern Manhattan Stroke Study (NOMASS) originally included a population-based incidence study and a nested casecontrol study designed to determine stroke incidence, risk factors, and prognosis in a multi-ethnic urban population. Details of the study have been previously published $[11,12]$, and will be summarized briefly.

\section{Selection of Subjects for Incidence Study and Index Ischemic}

Stroke Evaluation

Subjects were enrolled in the incidence portion of the study if they: (1) were diagnosed with first stroke (as defined by the National Institute of Neurological Disorders and Stroke, NINDS, Classification of Cerebrovascular Diseases III [13]) between 1993 and 1997; (2) were $\geq 40$ years old; (3) had resided in northern Manhattan for $\geq 3$ months in a household with a telephone. Over $80 \%$ of patients with stroke in northern Manhattan are hospitalized at the Columbia University Medical Center (CUMC). Subjects hospitalized at other local hospitals were identified through active surveillance of admissions and through local physicians. Approximately 5\% of incident ischemic stroke patients in northern Manhattan are not hospitalized [14]. Evaluation of patients was performed at the hospital, and those subjects that were not hospitalized at the CUMC were evaluated in the research clinic. For the incidence study, all cases of stroke within 4 zip codes of the census district were included.

\section{Selection of Subjects for Nested Case-Control Study}

All incidence cases that were evaluated in-person and stroke cases identified in another neighborhood zip code were enrolled in the population-based case-control study and were 1:2 matched to community controls by age, gender, and race-ethnicity. The methods of control procurement and enrollment have been described in detail in a previous publication [12]. Briefly, random digit dialing was performed by Audits and Surveys (New York, N.Y., USA). Community control subjects were enrolled if they: (1) had never been diagnosed with stroke; (2) were aged $\geq 40$ years; (3) had resided in northern Manhattan for at least 3 months in a household with a telephone. In-person evaluations were performed at the hospital or at home for those who could not come in person. The telephone response rate was $94 \%$, and $70 \%$ of those respondents participated in an in-person evaluation. The study was approved by the institutional review boards at the CUMC and other primary hospitals. All stroke cases and stroke-free control subjects gave consent directly or through a surrogate when appropriate.

Assessment of Race-Ethnicity and Risk Factors

Data were collected through interviews by trained research assistants, and physical and neurological examinations were conducted by study neurologists. When possible, data were obtained directly from subjects. When subjects were unable to provide answers, proxies were interviewed (29.1\% of the cases). Assessments were conducted in the participant's primary language. Race-ethnicity was based upon self-identification through a series of questions modeled after the US census, and conforming to standard definitions outlined by Directive 15 [15]. Participants who responded affirmatively to the question 'Are you of Hispanic/Spanish origin?' were classified as Hispanic. All other participants were then asked to classify their race into 1 of 6 categories: white, black, American Indian, Eskimo, Asian/Pacific Islander, or other. A proxy family member or caregiver was used for patients who were unable to answer questions because of coma, aphasia, etc.

Standardized questions were adapted from the Behavioral Risk Factor Surveillance System by the Centers for Disease Control and Prevention regarding the following conditions: HTN, $\mathrm{DM}$, hypercholesterolemia, peripheral vascular disease, transient ischemic attack, cigarette smoking, and cardiac conditions (myocardial infarction, coronary artery disease, angina, congestive heart failure, atrial fibrillation, other arrhythmias, and valvular heart disease). Definitions of risk factors such as HTN, DM, hypercholesterolemia, coronary artery disease, metabolic syndrome, and smoking have been previously published [10-12].

\section{Ischemic Stroke Subtype Classification}

The participants' histories, neurological examinations, and diagnostic evaluations (CT, MRI, MR angiography, carotid Doppler, transcranial Doppler, ECG, transesophageal or transthoracic echocardiogram, Holter monitoring, and conventional catheter angiography) were abstracted from the medical record. A panel of NOMASS neurologists blinded to patient identifiers, sex, race-ethnicity, risk factors (except history of transient ischemic attack, atrial fibrillation, and any other heart condition), and outcome, classified each stroke case according to modified TOAST (Trial of Org 10172 in Acute Stroke Treatment) criteria [16] into infarction due to atherosclerosis, embolism from a commonly accepted cardiac source, lacune, cryptogenic infarction, and stroke from other unusual causes using the best available information, as previously described [17]. Atherosclerotic stroke was attributed to perfusion failure distal to the site of severe stenosis or occlusion, or it represented cases where the stenosis was insufficient in itself to account for stroke on hemodynamic grounds but possibly served as an embolic source. This subtype characterized patients who usually presented with focal neurological symptoms and signs, brain-imaging evidence of a superficial or large deep infarction, and evidence of stenosis or occlu- 
sion detected by Doppler sonography or angiography. Atherosclerotic stroke was subdivided into extracranial atherosclerosis (EATH) or IATH categories depending on the location of the stenosis or occlusion. Extracranial sites included the common and internal carotid arteries at the bifurcation and the extradural portions of the vertebral arteries. Intracranial sites included the internal carotid siphon, middle cerebral artery stem or branches, anterior cerebral artery, intradural vertebral artery, basilar artery, and posterior cerebral artery stem. Classification as extracranial atherosclerotic disease required more than $60 \%$ stenosis in the symptomatic carotid artery or occlusion or high-resistance flow in the vertebral artery. Doppler criteria (Diasonics) for stenosis or occlusion were $60-80 \%$ stenosis when the ratio of internal to common carotid artery velocity was $>3.0$ with no or minimal aliasing; 80-99\% stenosis when the internal carotid artery peak velocity was $>190 \mathrm{~cm} / \mathrm{s}$, turbulence was present, and aliasing was detected; occlusion when no flow was detected in a well-imaged artery lumen; and high-resistance flow when there was no detectable anterograde flow in diastole. TCD measurements were made of the middle, anterior, posterior cerebral, and basilar arteries using EME Carolina equipment with a $2-\mathrm{MHz}$ probe. Segmental arterial velocities were recorded and compared on either side, with evidence of intracranial stenosis based on the finding of a significant asymmetry (ratio $>2.0$ ) between the peak velocities of the ipsilateral to contralateral arteries or a peak velocity $>120 \mathrm{~cm} / \mathrm{s}$ in the symptomatic artery. If conventional cerebral angiography or magnetic resonance angiography was performed, an occlusion or $>60 \%$ stenosis of the symptomatic internal carotid origin or vertebral artery was required for the diagnosis of extracranial atherosclerosis; evidence of focal narrowing or occlusion of the symptomatic intracranial artery was required for intracranial atherosclerosis [2]. Patients with inadequate evaluations, conflicting data, or adequate evaluations that failed to confirm the initial impression of the stroke subtype were diagnosed with cryptogenic infarction. This ensured a more specific classification of the atherosclerotic diagnostic categories. Consensus was reached by discussion, and disagreements were adjudicated by one of the principal investigators (R.L.S.).

\section{Statistical Analysis}

Average annual incidence rates stratified by age, gender, and ethnicity were calculated as follows: number of first stroke patients identified divided by the white/black/Hispanic northern Manhattan population according to 1990 US census. Direct age-adjusted rates with standard errors were calculated using age-specific proportions from the northern Manhattan population for each raceethnicity subgroup. Relative incidence rates for each ischemic stroke subtype were obtained by division of the rate in the Hispanic or black population by the white reference group. We used $\chi^{2}$ and Student $t$ tests to compare race-ethnic differences in risk factors, sociodemographics, and proportions of ischemic subtypes. Conditional logistic regression was used to estimate the odds ratio (OR) for matched case-control pairs for various vascular risk factors before and after adjustment for sociodemographic variables and other traditional vascular risk factors, such as educational level, HTN, alcohol abuse, smoking, obesity, physical inactivity, and serum LDL/HDL levels. A test for homogeneity was used to assess significant differences across the calculated OR and confidence intervals (CI). Statistical analyses were conducted using SAS version 9.1 (SAS Institute) and significance was set at $\mathrm{p}<0.05$.

\section{Results}

\section{Description of the Cohort}

Over 4 years, 714 individuals with first ischemic stroke were identified within the northern Manhattan population. The mean age at baseline was $60 \pm 10$ years; $63 \%$ were women; $29 \%$ were white, $22 \%$ were black, and $49 \%$ were Hispanic (55\% from the Dominican Republic, 13\% from Puerto Rico, 11\% from Cuba, 21\% other/unknown). Of these subjects, $95 \%$ were hospitalized, and all subjects underwent neuroimaging (98\% CT, 43\% MRI), 86\% underwent duplex Doppler, 54\% had transcranial Doppler, $18 \%$ had MR angiography, $88 \%$ underwent transthoracic echo, $21 \%$ had transesophageal echo, $10 \%$ had Holter monitoring, and $3 \%$ had conventional catheter angiography. At least one form of intracranial vascular imaging, MR angiography, transcranial Doppler, or angiography, was performed in $61 \%$ of patients. The stroke diagnostic evaluation was considered inadequate among only 7.3\% of the 509 patients who underwent in-person interview, with no significant difference by race-ethnicity [3].

\section{Cerebral Infarct Subtypes and Race-Ethnicity}

The overall crude incidence of IATH was 8/100,000 per year, which accounted for $7 \%$ of ischemic strokes (fig. 1), and the mean age for IATH was $67 \pm 13$ years. The specific incidence rate of stroke attributed to IATH was higher (11/100,000 per year) than for EATH (5/ 100,000 per year) in the 45 - to 54 -year age group. A higher specific incidence rate for IATH- (44/100,000 per year) related stroke was also seen in the $75+$ age group (fig. 2). Additionally, the relative incidence rate for IATH was higher among blacks (5.9/100,000 per year) and Hispanics (5/100,000 per year) compared to EATH (fig. 3).

\section{Cerebral Infarct Subtypes and Vascular Risk Factors}

In the univariate analysis, subjects with IATH stroke had a higher prevalence of DM (67\% for IATH, $60 \%$ for EATH, $48 \%$ for non-atherosclerotic (NATH), and 23\% for controls; $\mathrm{p}<0.05$ IATH vs. control) and of metabolic syndrome (62\% for IATH, $40 \%$ for EATH, $40 \%$ for NATH, and $35 \%$ for controls; $\mathrm{p}<0.05$ IATH vs. control) (table 1). The prevalence of other risk factors such as sex, HTN, coronary artery disease, and hypercholesterolemia was similar across stroke subtypes (table 1). In the multivariate model, DM conferred a significantly higher risk for IATH over NATH (adjusted OR, 10.8; 95\% CI, 2.0-57 vs. adjusted OR, 2.7; 95\% CI, 1.9-3.9, p < 0.05) and EATH (adjusted OR, 6.2; 95\% CI, 1.2-32) (table 2). Similarly, the metabolic syndrome (OR, 4.6; 95\% CI, 1.1-18.7) had a

Incidence and Risk Factors of 


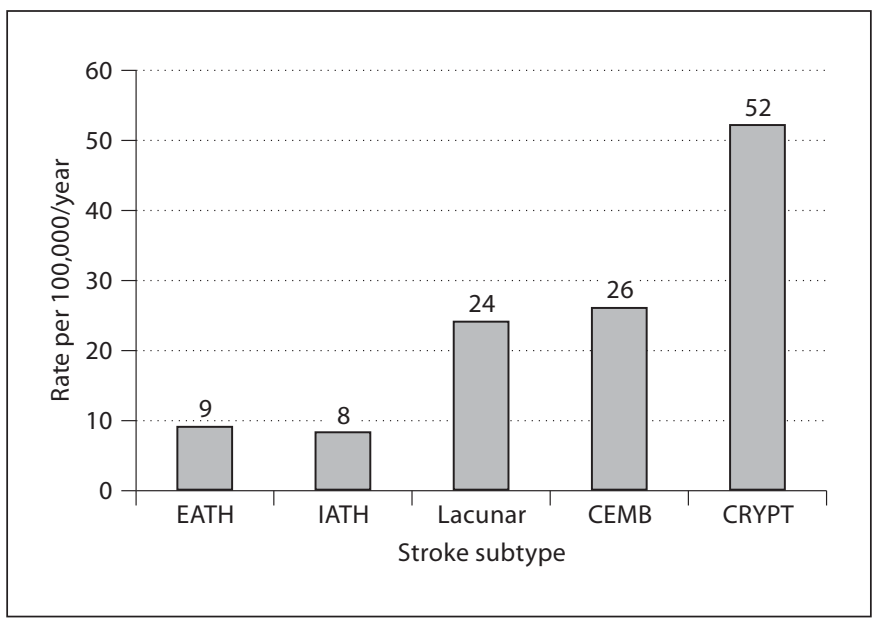

Fig. 1. Average annual overall crude incidence rate by stroke subtype. $\mathrm{CEMB}=$ Coronary embolism; $\mathrm{CRYPT}=$ cryptogenic infarc tion.

larger magnitude of association with the IATH stroke subtype when compared to EATH (OR, 2.3; 95\% CI, 0.69.1) and NATH (OR, 2.4; 95\% CI, 1.7-3.3), but the test for homogeneity was not significant (table 2).

\section{Discussion}

This analysis provides updated estimates of incidence rates of specific ischemic stroke subtypes in a multi-ethnic urban cohort from the northern Manhattan community $[3,17]$. As we have previously described, the raceethnic variation in stroke incidence was not equal across all stroke subtypes [3], with the greatest disparity seen in the relative incidence rates for IATH among blacks and Hispanics compared to whites [2, 17] (fig. 3). Additionally, we found that DM and the metabolic syndrome conferred a higher risk to develop IATH as compared to EATH and NATH stroke subtypes (table 2), and that the risk was independent of other risk factors such as HTN, HDL/LDL cholesterol levels, alcohol consumption, smoking, and physical activity.

In our cohort, the overall crude incidence of IATH was $8 / 100,000$ per year, which accounted for $7 \%$ of all ischemic strokes. The lower incidence in this study may be explained by several factors. First, studies that are not population-based may have some selection bias to include more cases of IATH who may end up on stroke services. Second, older studies, in which atherosclerotic infarction was diagnosed, adjudicated etiological stroke

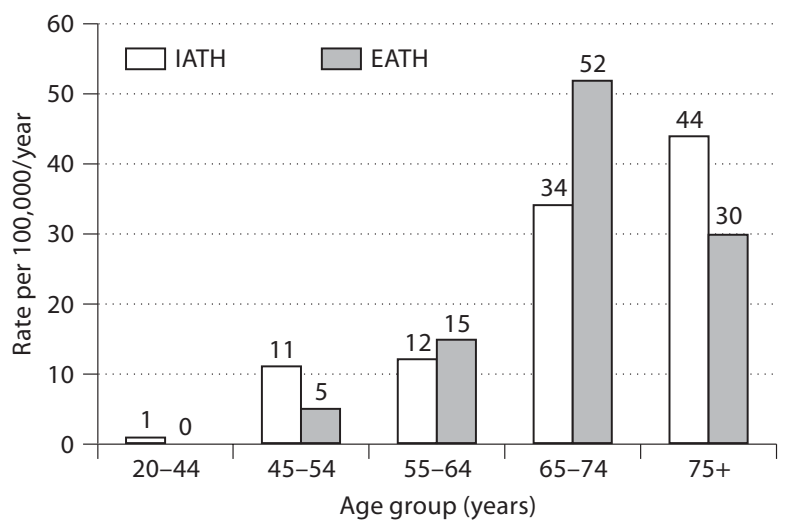

Fig. 2. Average annual age-specific incidence rates per stroke subgroup.

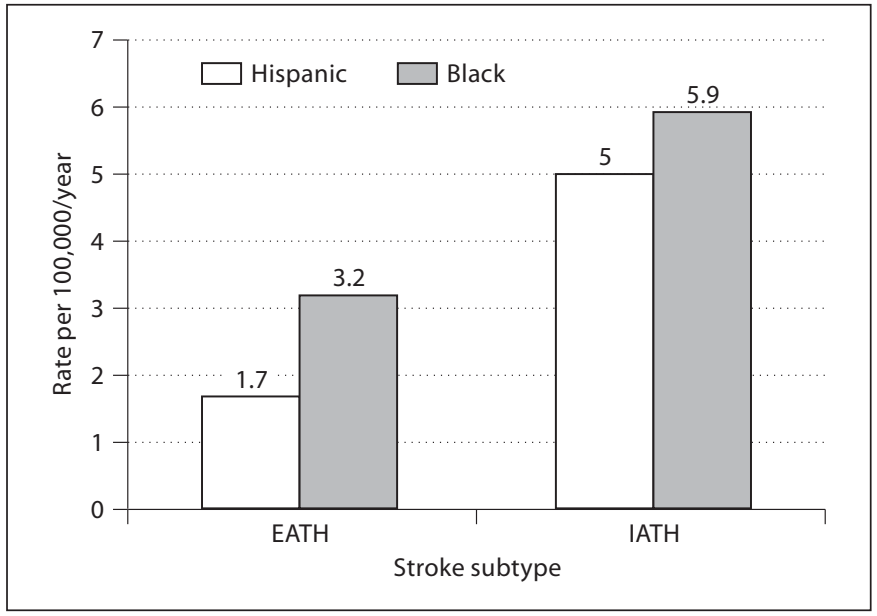

Fig. 3. Relative incidence of IATH and EATH by race-ethnicity compared to whites as the reference group.

mechanisms based on presumed mechanisms and not confirmatory laboratory data $[4,18,19]$. Third, the methodology by which stroke mechanism was adjudicated in NOMASS used several modalities, including cerebral angiography, transcranial Doppler, magnetic resonance angiography, and autopsy, making the diagnosis of IATH more attainable. And fourth, unlike other studies, NOMASS used a cryptogenic stroke-subtype group and when patients had insufficient data to be reliably categorized, they were classified as cryptogenic infarctions. It is 
Table 1. Prevalence and mean values of vascular risk factors by stroke subtype (case-control)

\begin{tabular}{lccccc}
\hline & $\begin{array}{c}\text { IATH } \\
(\mathrm{n}=52)\end{array}$ & $\begin{array}{c}\text { EATH } \\
(\mathrm{n}=50)\end{array}$ & $\begin{array}{l}\text { NATH } \\
(\mathrm{n}=559)\end{array}$ & $\begin{array}{l}\text { Control } \\
(\mathrm{n}=1,153)\end{array}$ & $\begin{array}{l}\text { p value (IATH } \\
\text { vs. controls) }\end{array}$ \\
\hline Male gender, \% & 46 & 44 & 44 & 39 & n.s. \\
HTN, \% & 87 & 88 & 82 & 71 & n.s. \\
Coronary artery disease, \% & 27 & 28 & 38 & 24 & n.s. \\
DM, \% & 67 & 60 & 48 & 23 & $<0.05$ \\
History of hypercholesterolemia, \% & 56 & 48 & 39 & 48 & n.s. \\
Metabolic syndrome, \% & 62 & 40 & 40 & 35 & $<0.05$ \\
Age, years & 67 & 70 & 70 & 70 & $<0.05$ \\
Systolic BP, mm Hg & 146 & 142 & 143 & 142 & n.s. \\
Diastolic BP, mm Hg & 79 & 81 & 83 & 82 & n.s. \\
Pulse pressure, mm Hg & 67 & 61 & 60 & 61 & $<0.05$ \\
Fasting glucose, mg/dl & 195 & 176 & 159 & 110 & $<0.05$ \\
LDL cholesterol, mg/dl & 130 & 124 & 120 & 123 & n.s. \\
HDL cholesterol, mg/dl & 40 & 40 & 41 & 48 & n.s. \\
Triglycerides, mg/dl & 163 & 171 & 150 & 138 & n.s. \\
\hline
\end{tabular}

Non-percentages expressed as mean values.

Table 2. Association of vascular risk factors and stroke subtype (case-control)

\begin{tabular}{lllll}
\hline & $\begin{array}{l}\text { DM } \\
(\text { adjusted OR }\end{array}$ & $\begin{array}{l}\text { Homogeneity across } \\
\text { subtypes (p value) }\end{array}$ & $\begin{array}{l}\text { Metabolic syndrome } \\
\left.\text { (adjusted OR }{ }^{1}\right)\end{array}$ & $\begin{array}{l}\text { Homogeneity across } \\
\text { subtypes (p value) }\end{array}$ \\
\hline IATH & $10.8(2.0-57)$ & $<0.05($ IATH vs. NATH) & $4.6(1.1-18.7)$ & n.s. (IATH vs. NATH) \\
EATH & $6.2(1.2-32)$ & n.s. (EATH vs. NATH) & $2.3(0.6-9.1)$ & n.s. (EATH vs. NATH) \\
NATH & $2.7(1.9-3.9)$ & - & $2.4(1.7-3.3)$ & -
\end{tabular}

${ }^{1}$ Models adjusted for HTN, HDL and LDL cholesterol, obesity, alcohol, smoking, and physical activity.

still possible that we underestimated the true incidence of IATH by missing some cases classified in the cryptogenic category.

Although the incidence of IATH increased with age, among those aged 45-54 years, the incidence of IATH was more than two-fold greater than EATH. This finding may result from the race-ethnic variation in IATH. Blacks and Hispanics who are younger than whites in the northern Manhattan community have a greater incidence of IATH, and the higher incidence of IATH may be explained by the greater prevalence of DM and metabolic syndrome among these ethnic groups $[17,20]$. There are differences in risk factors between northern Manhattan whites, blacks, and Hispanics and despite being significantly younger, the black and Hispanic northern Manhattan populations have a higher overall risk factor bur- den and a different risk factor profile than the white population [20].

Race-ethnicity may be a determinant of IATH stroke subtype as this has also been consistently reported by many other studies $[4,6,18,19,21,22]$ and by NOMASS $[2,3,7]$. However, race-ethnic differences in ischemic stroke subtypes may be due to variations in risk factor burden across these ethnic subgroups and possibly to genetic susceptibility. Previous studies $[18,21]$ and NOMASS [2], have shown that blacks are more likely to develop IATH than other populations, especially in the anterior circulation compared to the extracranial carotid or vertebral arteries, and autopsy studies of the intracranial arteries have also confirmed this association [22]. These studies have attempted to address the racial differences in IATH, confirming an increased prevalence of certain 
stroke risk factors in these race-ethnic groups [18, 19], but in those studies Hispanics were not separately studied.

In our case-control study, a higher proportion of DM was found in all stroke subtypes compared to controls, but this was particularly higher in the IATH stroke subtype (67 vs. $60 \%$ in EATH, $48 \%$ in NATH, and $23 \%$ in controls; $\mathrm{p}<0.05$ IATH vs. controls) (table 1) suggesting a higher prevalence of DM in the IATH stroke subtype. In our multivariate analysis, DM conferred a higher risk for IATH versus NATH stroke subtype (adjusted OR, 10.8 ; 95\% CI, 2.0-57 vs. adjusted OR, 2.7; 95\% CI, 1.9-3.9; $\mathrm{p}<0.05$ ) and lower for EATH (adjusted OR, 6.2; 95\% CI, 1.2-32) (table 2). Similarly, the proportion of metabolic syndrome was higher in the IATH subgroup compared to the other stroke subtypes (62 vs. $40 \%$ in EATH, $40 \%$ in $\mathrm{NATH}$, and $35 \%$ in controls), and the multivariate analysis confirmed the independent association between the metabolic syndrome and IATH stroke subtype. Interestingly, metabolic syndrome was also significantly associated with NATH. NOMASS has previously reported on the significant association between ischemic stroke and metabolic syndrome, and this association may even exist in the NATH stroke subtype [10] constituting a novel therapeutic target for populations at risk.

The over-representation of DM and metabolic syndrome in IATH and the mechanisms by which these risk factors contribute to the overall risk of stroke in IATH are matters for future research, but serum markers of systemic inflammation and metabolic dysfunction seen in $\mathrm{DM}$ and the metabolic syndrome have been associated with higher rates of cardiovascular events in patients with stable and unstable atherosclerotic plaques [23]. The higher prevalence of these risk factors may accelerate the conversion of asymptomatic to symptomatic plaque in patients with IATH.

In recent studies, the metabolic syndrome has been shown to be a significant independent risk factor for cardiovascular disease $[9,24]$ and particularly for stroke $[10$, 24], but these studies have primarily focused on patients with extracranial vascular disease [25-27]. Recently, Bang et al. [5] reported on the association between metabolic syndrome and IATH, and concluded that metabolic syndrome was an independent predictor for IATH-related stroke. Our results support those conclusions, but those results may not be generalizable to all populations because their study was a single-center study in a Korean population and the comparison group included patients with NATH stroke subtype (lacunar and cardio-embolic) who may have had atherosclerosis as well. Our study design allowed us to compare different stroke subtypes to asymptomatic controls in a multi-ethnic cohort, making our results more generalizable.

Our study offers several advantages for the analysis of the prevalence of risk factors in IATH-related stroke across different race-ethnicities. It is a hospital and community-based prospective cohort, so selection and referral biases are minimized as the diagnosis of stroke subtype is more accurate and uniform across the different ethnic subgroups; our cohort study also includes Hispanics, who have not been represented in any previous population-based studies of ischemic stroke subtype incidence; our population-based surveillance system included hospitalized and non-hospitalized cases, although the 5\% proportion of non-hospitalized strokes may be smaller than that of other communities; and finally, study subjects were thoroughly investigated, and stroke subtype classification was performed by a team of neurologists who reached a consensus agreement, therefore minimizing misclassification.

The limitations of our analysis are based on the observational nature of our study, which may have limited the inferences that can be made about etiological relationships, and our matching design on age, sex, and race-ethnicity makes it difficult to specifically evaluate the association between these variables and IATH across different ethnic subgroups. Similarly, our analysis of etiological factors may have been underpowered to fully assess the associations between risk factors and different stroke subtypes. As in any other incidence study, complete capture of all cases cannot be substantiated, and the fact that not all subjects underwent a systematic investigation, including vascular imaging, could be a source of information bias. Whether our results are generalizable to other populations can always be argued as a potential limitation; however, our study provides important data for minority populations.

In summary, we have confirmed the incidence rate of IATH in a large prospective multi-ethnic cohort and the different prevalence of risk factors across stroke subgroups. DM is a more important determinant for IATH stroke than for EATH or NATH. These associations may explain the over-representation of IATH among blacks and Hispanics.

\section{Acknowledgments}

This paper was supported by grants to R.L.S. [NINDS: RO1 NS29993 (NOMASS) and P50 NS049060 (SPOTRIAS)]; F.R. was a SPOTRIAS fellow. 


\section{References}

1 Failure of extracranial-intracranial arterial bypass to reduce the risk of ischemic stroke: results of an international randomized trial. The EC/IC bypass study group. N Engl J Med 1985;313:1191-1200.

-2 Sacco RL, Kargman DE, Gu Q, Zamanillo MC: Race-ethnicity and determinants of intracranial atherosclerotic cerebral infarction: the Northern Manhattan Stroke Study. Stroke 1995;26:14-20.

$\checkmark 3$ White H, Boden-Albala B, Wang C, Elkind MS, Rundek T, Wright CB, Sacco RL: Ischemic stroke subtype incidence among whites, blacks, and Hispanics: the Northern Manhattan Study. Circulation 2005;111:13271331.

4 Wityk RJ, Lehman D, Klag M, Coresh J, Ahn $\mathrm{H}$, Litt B: Race and sex differences in the distribution of cerebral atherosclerosis. Stroke 1996;27:1974-1980.

5 Bang OY, Kim JW, Lee JH, Lee MA, Lee PH, Joo IS, Huh K: Association of the metabolic syndrome with intracranial atherosclerotic stroke. Neurology 2005;65:296-298.

$\checkmark 6$ Feldmann E, Daneault N, Kwan E, Ho KJ, Pessin MS, Langenberg P, Caplan LR: Chinese-white differences in the distribution of occlusive cerebrovascular disease. Neurology 1990;40:1541-1545.

$\checkmark 7$ Sacco RL, Kargman DE, Zamanillo MC: Race-ethnic differences in stroke risk factors among hospitalized patients with cerebral infarction: The Northern Manhattan Stroke Study. Neurology 1995;45:659-663.

$>8$ Executive Summary of the Third Report of the National Cholesterol Education Program (NCEP) Expert Panel on Detection, Evaluation, and Treatment of High Blood Cholesterol in Adults (Adult Treatment Panel III). JAMA 2001;285:2486-2497.

$\checkmark 9$ Girman CJ, Rhodes T, Mercuri M, Pyorala K, Kjekshus J, Pedersen TR, Beere PA, Gotto AM, Clearfield M: The metabolic syndrome and risk of major coronary events in the Scandinavian Simvastatin Survival Study (4s) and the Air Force/Texas Coronary Atherosclerosis Prevention Study (AFCAPS/ TEXCAPS). Am J Cardiol 2004;93:136-141.

$\checkmark 10$ Boden-Albala B, Sacco RL, Lee HS, Grahame-Clarke C, Rundek T, Elkind MV, Wright C, Giardina EG, DiTullio MR, Homma S, Paik MC: Metabolic syndrome and ischemic stroke risk: Northern Manhattan Study. Stroke 2008;39:30-35.
11 Sacco RL, Elkind M, Boden-Albala B, Lin IF, Kargman DE, Hauser WA, Shea S, Paik MC: The protective effect of moderate alcohol consumption on ischemic stroke. JAMA 1999;281:53-60.

12 Sacco RL, Gan R, Boden-Albala B, Lin IF, Kargman DE, Hauser WA, Shea S, Paik MC: Leisure-time physical activity and ischemic stroke risk: The Northern Manhattan Stroke Study. Stroke 1998;29:380-387.

13 Special report from the National Institute of Neurological Disorders and Stroke. Classification of Cerebrovascular Diseases III. Stroke 1990;21:637-676.

14 Sacco RL, Boden-Albala B, Gan R, Chen X, Kargman DE, Shea S, Paik MC, Hauser WA: Stroke incidence among white, black, and Hispanic residents of an urban community: the Northern Manhattan Stroke Study. Am J Epidemiol 1998;147:259-268.

15 Race and Ethnic Standards for Federal Statistics and Administrative Reporting (Directive No. 15). Office of Management and Budget, Federal Register, 1978, vol 43, p 19269.

16 Adams HP Jr, Woolson RF, Clarke WR, Davis $\mathrm{PH}$, Bendixen $\mathrm{BH}$, Love $\mathrm{BB}$, Wasek $\mathrm{PA}$, Grimsman KJ: Design of the Trial of Org 10172 in Acute Stroke Treatment (TOAST). Control Clin Trials 1997;18:358-377.

17 Sacco RL, Roberts JK, Boden-Albala B, Gu Q, Lin IF, Kargman DE, Berglund L, Hauser WA, Shea S, Paik MC: Race-ethnicity and determinants of carotid atherosclerosis in a multiethnic population: the Northern Manhattan Stroke Study. Stroke 1997;28:929935.

18 Gorelick PB, Caplan LR, Hier DB, Patel D, Langenberg P, Pessin MS, Biller J, Kornack D: Racial differences in the distribution of posterior circulation occlusive disease. Stroke 1985;16:785-790.

19 Inzitari D, Hachinski VC, Taylor DW, Barnett HJ: Racial differences in the anterior circulation in cerebrovascular disease: how much can be explained by risk factors? Arch Neurol 1990;47:1080-1084.

20 Sacco RL, Boden-Albala B, Abel G, Lin IF, Elkind M, Hauser WA, Paik MC, Shea S: Race-ethnic disparities in the impact of stroke risk factors: the Northern Manhattan Stroke Study. Stroke 2001;32:1725-1731.
21 Qureshi AI, Safdar K, Patel M, Janssen RS, Frankel MR: Stroke in young black patients: risk factors, subtypes, and prognosis. Stroke 1995;26:1995-1998.

22 Williams AO, Resch JA, Loewenson RB: Cerebral atherosclerosis - a comparative autopsy study between Nigerian negroes and American negroes and Caucasians. Neurology 1969;19:205-210.

-23 Naghavi M, Libby P, Falk E, Casscells SW, Litovsky S, Rumberger J, Badimon JJ, Stefanadis C, Moreno P, Pasterkamp G, Fayad Z, Stone PH, Waxman S, Raggi P, Madjid M, Zarrabi A, Burke A, Yuan C, Fitzgerald PJ, Siscovick DS, de Korte CL, Aikawa M, Juhani Airaksinen KE, Assmann G, Becker CR, Chesebro JH, Farb A, Galis ZS, Jackson C, Jang IK, Koenig W, Lodder RA, March K, Demirovic J, Navab M, Priori SG, Rekhter MD, Bahr R, Grundy SM, Mehran R, Colombo A, Boerwinkle E, Ballantyne C, Insull W Jr, Schwartz RS, Vogel R, Serruys PW, Hansson GK, Faxon DP, Kaul S, Drexler H, Greenland P, Muller JE, Virmani R, Ridker PM, Zipes DP, Shah PK, Willerson JT: From vulnerable plaque to vulnerable patient: a call for new definitions and risk assessment strategies. Part I. Circulation 2003;108: 1664-1672.

24 Ninomiya JK, L'Italien G, Criqui MH, Whyte JL, Gamst A, Chen RS: Association of the metabolic syndrome with history of myocardial infarction and stroke in the Third National Health and Nutrition Examination Survey. Circulation 2004;109:42-46.

$>25$ McNeill AM, Rosamond WD, Girman CJ, Heiss G, Golden SH, Duncan BB, East HE, Ballantyne C: Prevalence of coronary heart disease and carotid arterial thickening in patients with the metabolic syndrome (the ARIC study). Am J Cardiol 2004;94:12491254.

26 Olijhoek JK, van der Graaf Y, Banga JD, Algra A, Rabelink TJ, Visseren FL: The metabolic syndrome is associated with advanced vascular damage in patients with coronary heart disease, stroke, peripheral arterial disease or abdominal aortic aneurysm. Eur Heart J 2004;25:342-348.

27 Scuteri A, Najjar SS, Muller DC, Andres R, Hougaku H, Metter EJ, Lakatta EG: Metabolic syndrome amplifies the age-associated increases in vascular thickness and stiffness. J Am Coll Cardiol 2004;43:1388-1395. 